\title{
MEASUREMENT, CALIBRATION OF RAINFALL-RUNOFF MODELS AND ASSESSMENT OF THE RETURN PERIOD OF FLOODING EVENTS AT URBAN CATCHMENT KUMODRAZ IN BELGRADE
}

\author{
Jovan Despotović, Jasna Petrović and Nenad Jaćimović
}

Faculty of Civil Engineering, University of Belgrade, P.O. Box 895, 11000 Belgrade, Yugoslavia

\begin{abstract}
For the purpose of re-design and improvement of the combined sewer system at the Kumodraz catchment in Belgrade, measurements of rainfall and runoff at the catchment were established in late 1997. Observed data are used for calibration and validation of two rainfall-runoff models: the detailed model BEMUS (Belgrade Model) and a conceptual hydrologic model Visual OTTHYMO. The major facilities of the recommended solution for re-design of the existing system are three retention ponds and outlet into a trunk. The paper briefly presents assessment of design flows for these four locations of the catchment based on results from the calibrated models. Data on intense storms that caused severe flooding within the catchment (and also all over Belgrade and other parts of Serbia) in June and July 1999 are used for comparison of design flows with a real event. During these storms the flow gauging equipment at the catchment was destroyed and only the rainfall data was available. In order to analyze the system under extreme conditions it is therefore necessary to perform hydrograph simulations. The basic idea was to check return periods of rainfall and runoff for these storms.
\end{abstract}

\section{KEYWORDS}

Rainfall-runoff; combined/separate systems; measurement; calibration; modelling; flood assessment

\section{INTRODUCTION}

The catchment of the Kumodraz brook in Belgrade is a typical catchment within the area of the Belgrade sewer system. This 775 ha catchment is of varying land use, ranging from rural areas in the upstream part to densely populated urbanized areas in the downstream part (Fig. 1). The brook exists until the middle of the catchment, where it is captured into the sewer system (point M in Fig. 1). The present sewer system, consisting of about 1000 pipes, is a mixture of the combined and separate stormwater and wastewater systems. The combined sewer system is dominant in the downstream part. The upstream part, subject to a rapid urbanization, is either without any sewer system (agricultural households) or with the separate system (newly urbanized areas). In this part stormwater gravitates toward the brook, and several wastewater outlets are directly discharged into the brook. The furthest lower part of the catchment is at great risk of surcharging from the combined system, what is unacceptable. Several industrial sites cause various kinds of pollution. Characteristic zones of the catchment Kumodraz that are shown in Fig. 1 are:

- Highly urbanized zone (U), with the combined sewer system. At the outlet of the catchment the main trunk sewer is connected to the trunk sewer of the larger catchment (point MD in Fig. 1) exactly below the highway route.

- Industrial zone (I) and the Kumodraz 2 settlement (K2), with separate stormwater and wastewater systems.

- Kumodraz 1 settlement (K1), with wastewater sewer system and no stormwater system.

- Urbanized zone named "Padina" (P) and the Kumodraz village (V), with no sewer systems. 


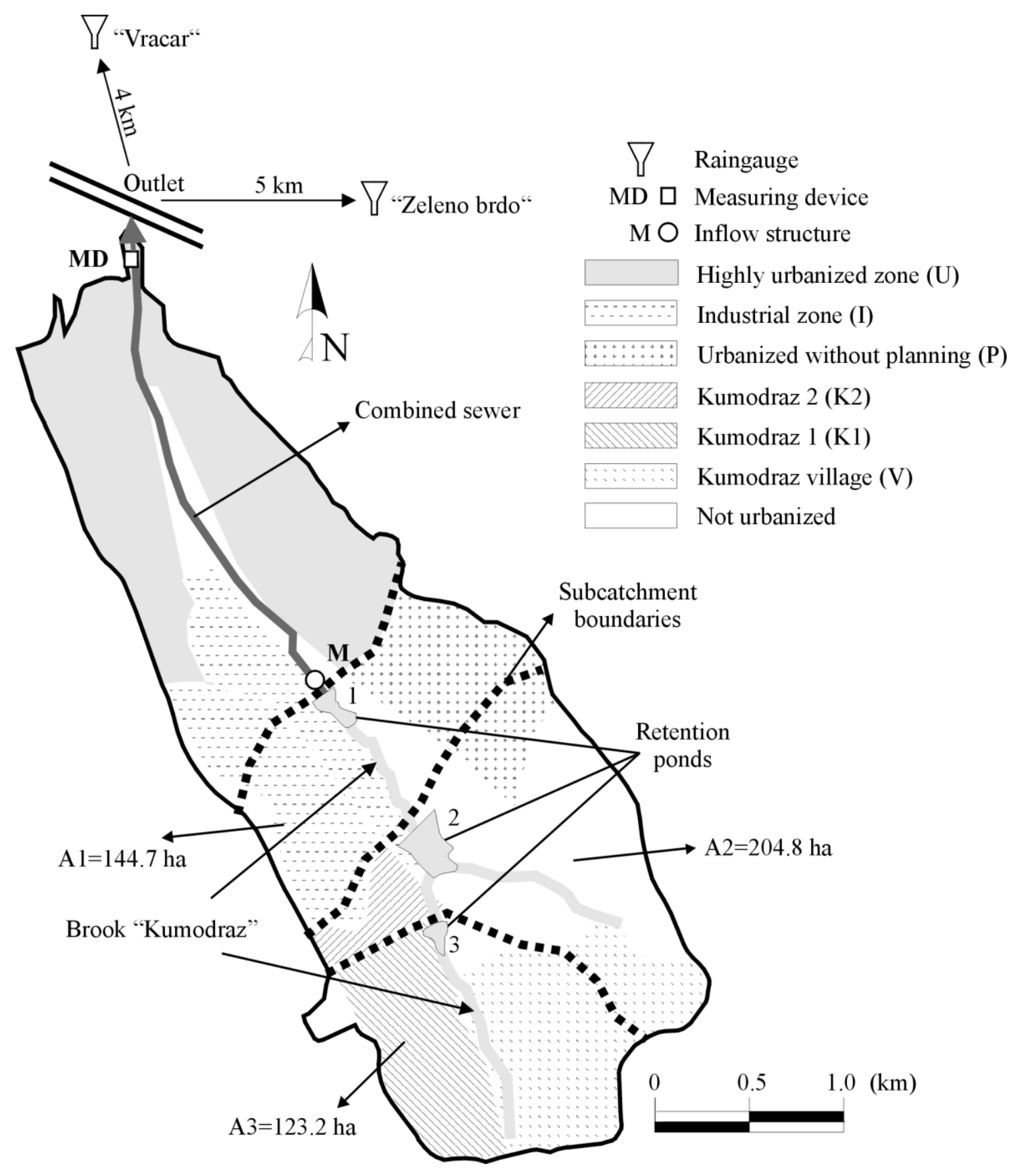

Figure 1. The Kumodraz catchment.

During 1997 and 1998 a study was carried out in order to evaluate the present state of the system and to propose a concept for re-design and improvement of the system (Despotović et al., 1998). The evaluation of the present state of the sewer system was based on runoff simulations using design storms of 2 years return period and on wastewater quantities for conditions at the catchment from spring/summer 1998. A general conclusion is that the combined sewer system in the zone $U$ is not sufficient for these conditions and therefore it has to be rehabilitated and reconstructed. Separate systems should be built in the zones V and P, and stormwater system in the zone K1.

The proposed design concept (given in more detail in a previous paper by Despotović et al, 1999) consists of the following requirements:

- Separation of stormwater and wastewater systems in the area of the combined system, and new separate systems in the non-drained areas.

- Efficient stormwater drainage without surcharging for return period of 2 years.

- Flood protection of the downstream highway for return period of 10 years.

- Flood protection of the catchment for return period greater than 2 years. 
- Preservation of the natural state of the Kumodraz brook wherever possible and its pollution control.

- Mitigation of the first-flush effect in the stormwater drainage system.

In this respect, a complex solution is proposed that consist of both reconstruction of the existing system and construction of new elements in the system. In the upstream part of the catchment, covering approximately $60 \%$ of total catchment area (400 ha), surface runoff should be retained for events with return periods up to 10 years, and significantly retained for floods up to 100 years return period. Emergency overflow structures were also checked for the 500-years events.

The flood control scheme that ensures proper operation of the drainage system is based upon the concept of retention ponds. A cascade of three retentions, located $0.3,1.0$ and $1.5 \mathrm{~km}$ upstream from the point $\mathrm{M}$ (inflow of the brook into the pipe) with total storage capacity of 175,000 cubic meters is proposed. The outflow structures are designed in such a way that the 10-years flood is completely retained, while the stormwater trunk is approximately full. The heights of retention dams $(5-8 \mathrm{~m})$ provide storage volume even for the 100-year floods with controllable flooding of the downstream areas.

\section{MEASUREMENTS AND MODEL CALIBRATION}

Using models without calibration and without measurements of rainfall and runoff is a very risky work. However, measurements performed within the scope of stormwater system design projects are always limited. Rainfall and runoff measurements at the Kumodraz catchment commenced in October 1997 and stopped in June 1999. Runoff was monitored at the outlet measuring structure (point MD in Fig. 1) reconstructed for this purpose. However, the flow gauging equipment was destroyed during severe flooding in June 1999 together with a data logger containing flow data recorded from April to June 1999.

During the period of measurements, no significant events were recorded. The largest one produced peak flow of $8 \mathrm{~m}^{3} / \mathrm{s}$ at the cathcment outlet, the return period of which is well below two years. Within the model calibration, surface retention and initial soil moisture parameters were assessed using these events. Fig. 2 presents an example of an event simulated with the calibrated Visual OTTHYMO model compared to the measurements at the catchment outlet. This is one of 20 events measured and tested in detail for accuracy and reliability.

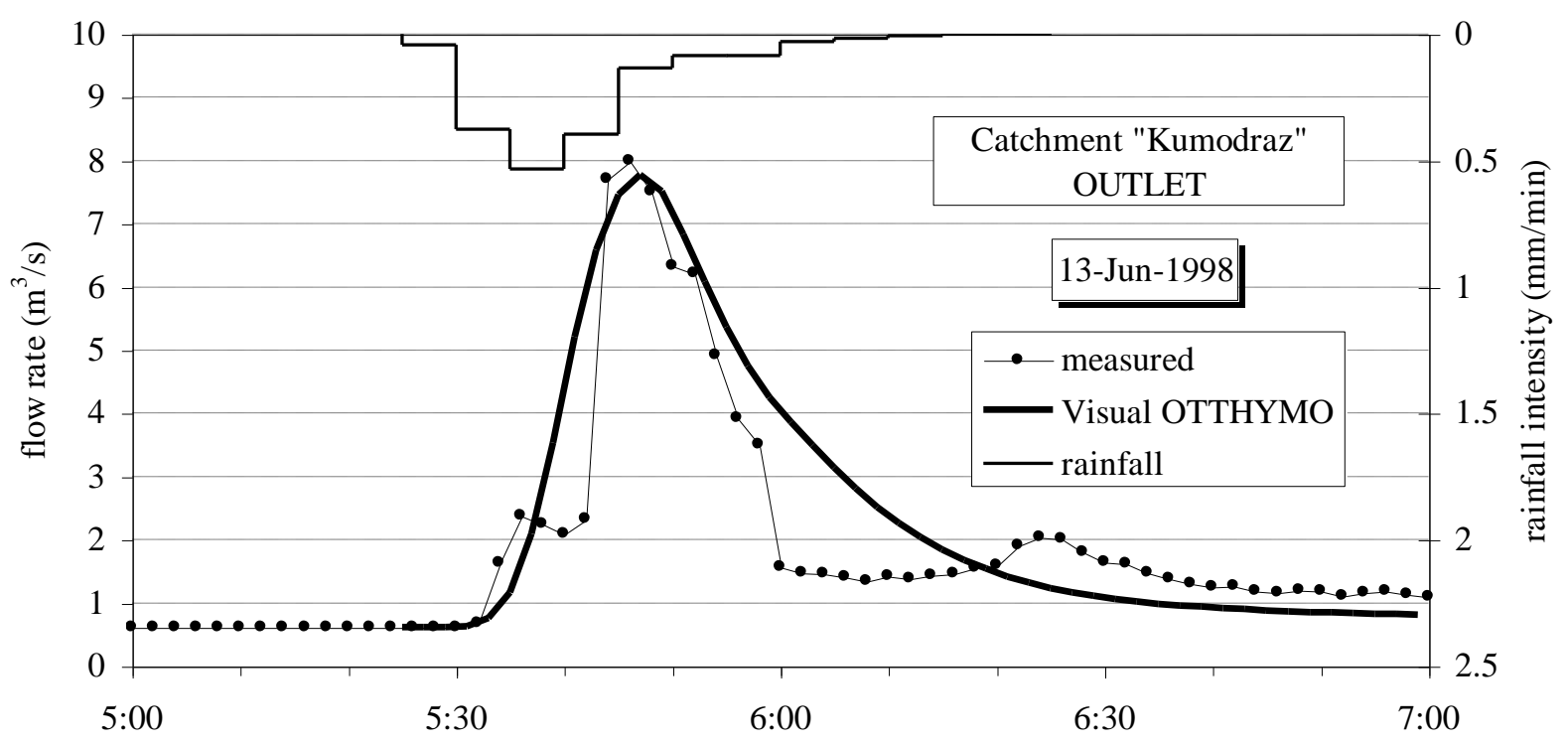

Figure 2. Comparison of measured and simulated hydrographs using the Visual OTTHYMO model calibrated with observed rainfall and runoff data. 
It is noteworthy that in 1999 the largest annual rainfall since 1892 was recorded in Belgrade. While the annual rainfall in Belgrade averages at $670 \mathrm{~mm}, 1120 \mathrm{~mm}$ was recorded during 1999, out of which $405 \mathrm{~mm}$ fell in June and July. During the event of June 1999 when the measuring equipment was destroyed, $66 \mathrm{~mm}$ of rain fell during less than 2 hours. The hyetograph of this storm is given in Fig. 3. Destruction of the measuring device was not an extraordinary incident comparing to the damage by flooding in vicinity.

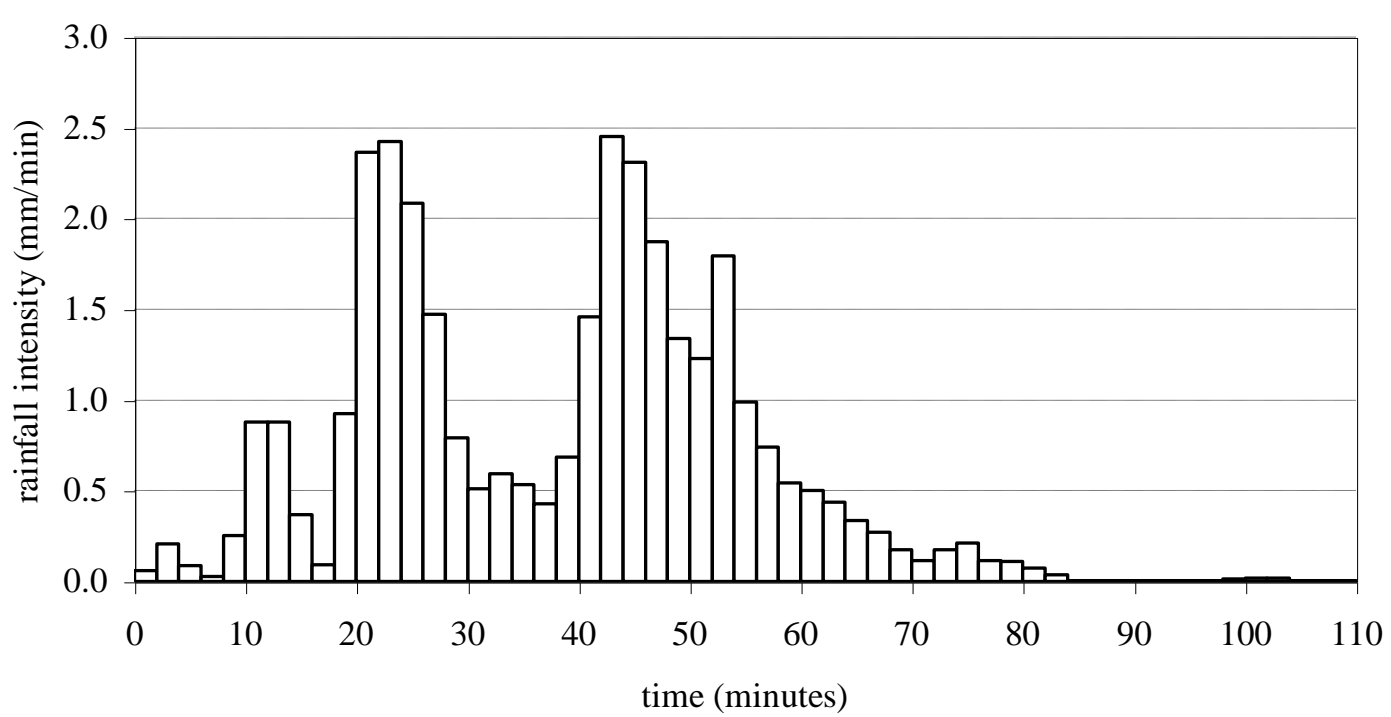

Figure 3. Hyetograph of the storm on June 15, 1999 (raingauge Zeleno Brdo).

\section{HYDROLOGICAL ANALYSIS}

Two approaches are applied for estimating design peak flows and volumes in the storm drainage system at the Kumodraz catchment: (1) design storms, and (2) statistically derived design flows and volumes from a series of simulated runoff hydrographs; hereafter, the historical storms approach (Petrović and Despotović, 1998).

Design storm analysis is performed with data from the Zeleno Brdo raingauge station (see Fig. 1), for which complete rainfall record was available. Rainfall depth-duration-frequency (DDF) curves, presented in Fig. 4, are established by standard frequency analysis, using the partial duration series method. Design storms are defined using dimensionless storm patterns obtained by statistical analysis of observed hyetographs (Vukmirović and Despotović, 1984). Maximum rainfall depths of different durations recorded during the flooding event on June 15, 1999 are added to the DDF curves in Fig. 4 for comparison, and are discussed in the following section.

In the historical storms approach, the complete record of historical storms is used to obtain a series of simulated runoff hydrographs, peak flows and volumes that are subject to the frequency analysis. Fig. 5 presents design flows obtained from historical and design storms. Corresponding design volumes are presented in Fig. 6, also based on the two sets of storms, and for four locations (outlet and three retentions: $\mathrm{R} 1, \mathrm{R} 2$, and R3). It should be noted that flows at these locations are calculated without taking into account the storage effect in order to obtain design flows for retention ponds and their structures. Storage effects are taken into analysis in the later phase of verification of the proposed system modifications.

Rainfall-runoff simulations were performed with the BEMUS model (Đorđević, 1999) and with the Visual OTTHYMO model (Greenland Eng. Group, 1997). BEMUS is a physically based model and was used for detailed analysis of the system for return periods of 2 and 10 years. OTTHYMO, as a conceptual lumped model, was used for analysis of the system for return periods of 10, 50 and 100 years. Both models were calibrated upon the flow measurements at the catchment outlet. 


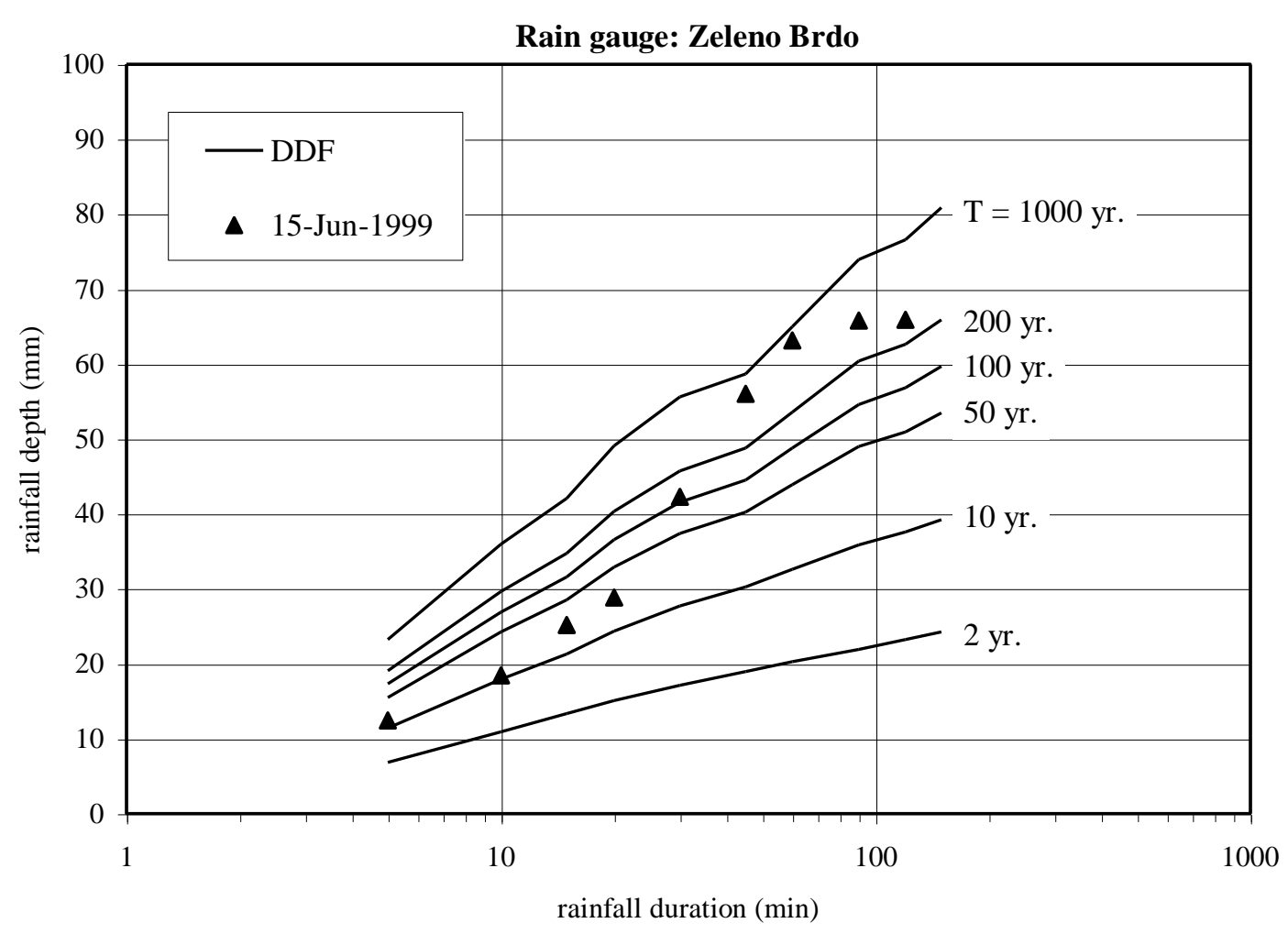

Figure 3. Rainfall depth-duration-frequency curves for rain gauge Zeleno Brdo in Belgrade and rainfall depths for different durations of the June 15, 1999 storm.

The design storm approach was used for the design of retention ponds for return periods of 50 and 100 years. The historical storm approach was used in the design procedure for obtaining the following design variables:

- 2-year design flow for the combined system in the urbanized zone and separate stormwater systems in other zones;

- 10-year design flows for the trunk stormwater sewer;

- 2-year and 10-year excess storm runoff for additional stormwater systems.

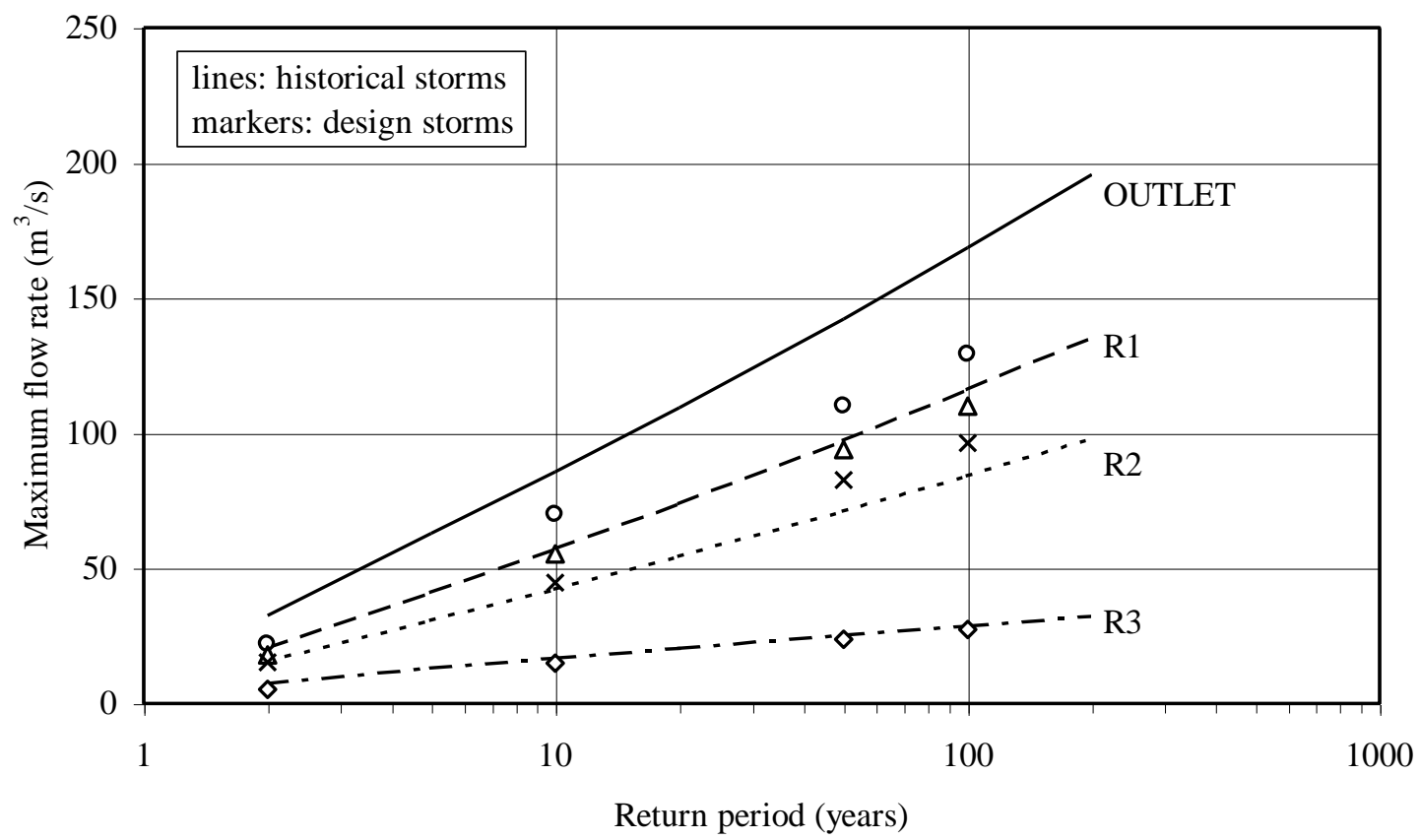

Figure 5. Design flows calculated with historical storms and with design storms. 


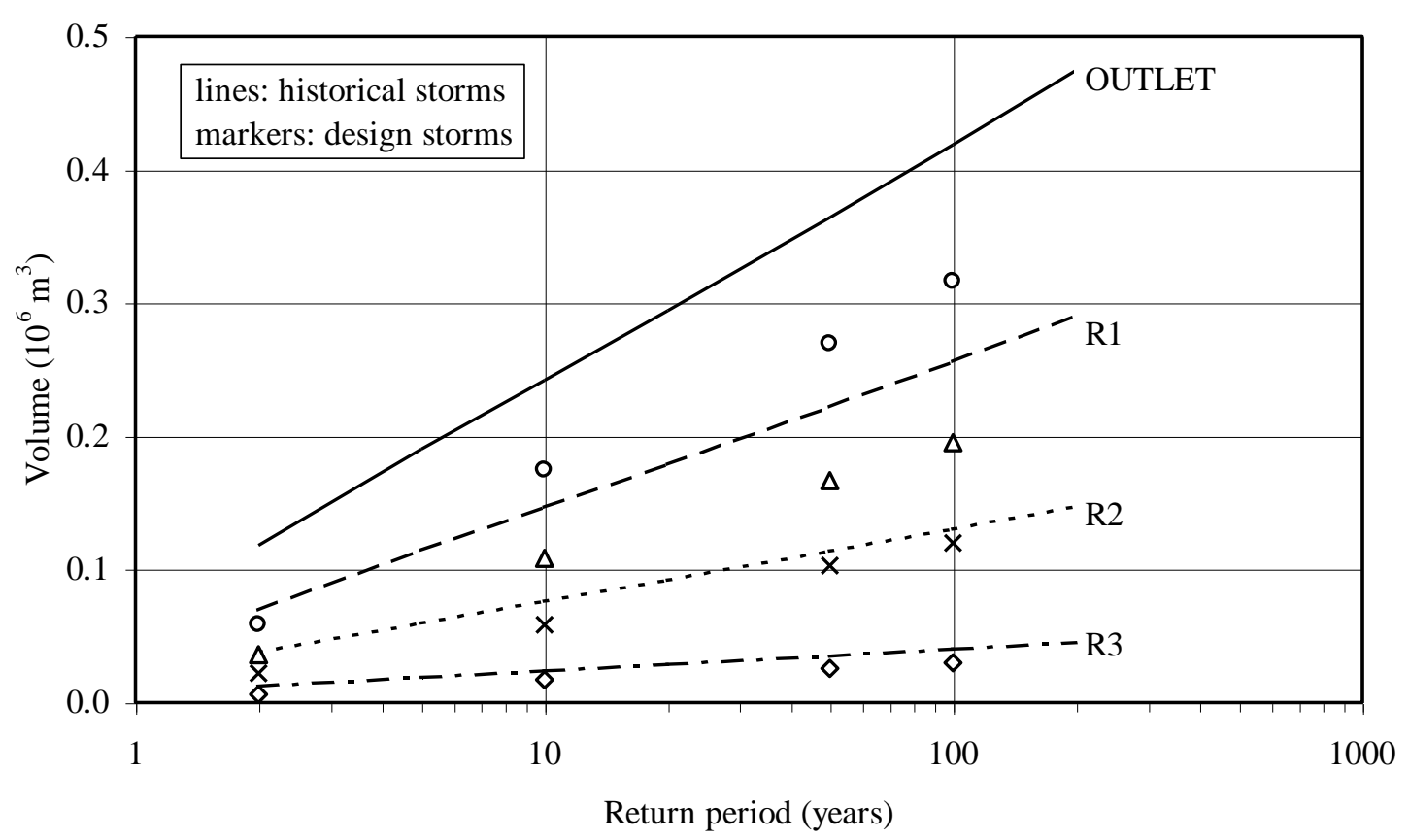

Figure 6. Design volumes calculated with historical storms and with design storms.

\section{ASSESSMENT OF THE RETURN PERIODS OF FLOODING EVENTS}

A series of historical flows used for design purposes are simulated from rainfall measurements using the BEMUS and the Visual OTTHYMO models. In order to discuss the applicability of the two models, the capacity of the existing pipes/trunks should be considered, i.e. the possibilities for occurrence of surface flow. A model for analysis and evaluation of design flow rates and volumes should be chosen according to the nature of the analyzed phenomenon. In other words, for runoff of low return period (up two or five years), a detailed model should be used. For events of higher return period (more than 10 years), a lumped model should be applied. This is because in such extreme conditions gutter inlets do not capture more than $20-30 \%$ of surface flow, so that surface flow should be modelled by either a lumped model or a detailed model capable of handling dual drainage concept. In our simulations the Visual OTTHYMO model is actually used as a lumped dual drainage model.

The storm of June 15, 1999 (Fig. 3) caused extraordinary flooding in many parts of Belgrade. The most severe flooding actually occurred in the downstream part of the Kumodraz catchment. In the area near the catchment outlet, as well as in the further downstream area extending in a highway corridor, depth of water was at least $1 \mathrm{~m}$.

Maximum rainfall depths of different durations recorded on June 15, 1999 are compared to the DDF curves in Fig. 4. It can be seen that this real storm has different return periods for various durations. This is true for all real/historical storms when compared to design storms. Comparing design flows to simulated flows from the storm of June 15, 1999 (Fig. 7) is also very instructive. Peak flow rates for this event at four locations within the catchment are drawn on the corresponding design flow frequency curves (there is a pair of flows for each location resulting from simulations based on rainfall recorded at two raingauge stations, Vracar and Zeleno Brdo, see Fig. 1). It is obvious that this severe event caused flooding of different frequencies at different locations. The more downstream the location is, the higher is the return period, i.e. the more severe is the flooding. This is in relation with the fact that different rainfall duration is significant for different subcatchments. 


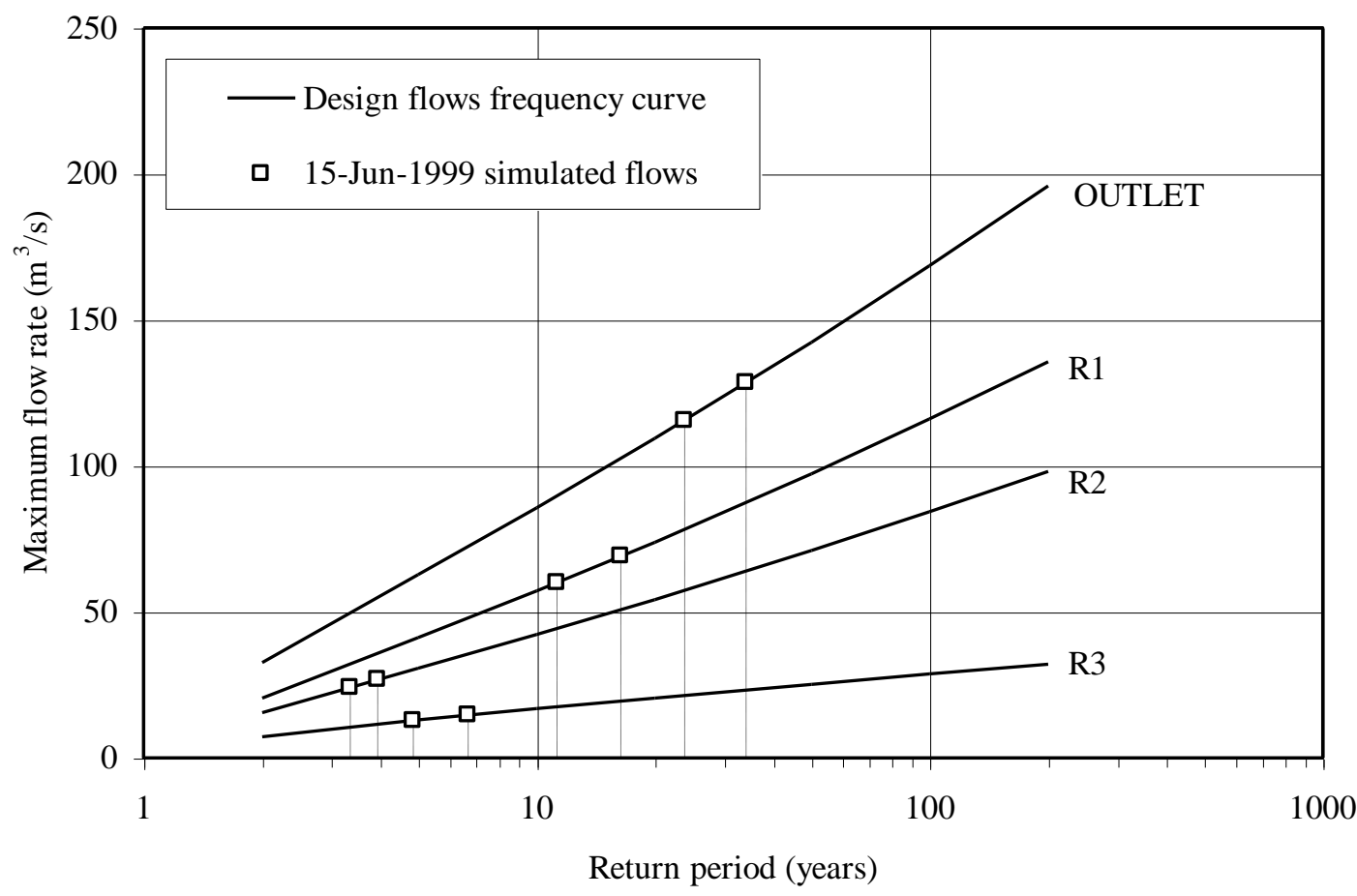

Figure 7. Frequency curves of flows for four locations within the catchment and simulated peak flows for the storm of June 15, 1999.

\section{CONCLUSIONS}

Although measurements in storm sewer systems are always of great importance, it is often a matter of time, weather and mostly luck that the measurements would last long enough to be used in frequency analysis. Moreover, the measurements should cover the whole range of flow rates within the sewers, so that exceeding sewer capacities and surcharging could be detected. It is most likely that among the observed rainfall-runoff events there will not be significant and extreme ones. During the short-term measurements at the Kumodraz catchment, just small and moderate events were recorded. Recording the extreme events, such as the event of June 1999 which damaged the measuring equipment, would be much more convenient than being forced to simulate flow rates and volumes.

The procedure for modelling rare events with a detailed model, which is often used, is not recommended because significant portion of water flows over streets, paved areas and pervious hill slopes and does not flow through the system, i.e. through the pipes and trunks. In such extreme situations, it is difficult to set the parameters of a detailed model to achieve fairly accurate surface flow calculations. Instead, lumped models with dual drainage modelling possibilities like Visual OTTHYMO are recommended for such analysis.

The storm of June 15, 1999 at the Kumodraz catchment caused severe flooding of different frequencies at different locations. The more downstream the location is, the higher is the return period, i.e. the more severe is the flooding. This has lead to final solution of the system which is comprised of all three retention ponds (R1, R2 and R3) instead of original solution in which these three retention ponds were considered as alternatives. Similar to the analysis of maximum flow rates (Fig. 7), the volumes could be analyzed.

In order to analyze runoff from natural and urbanized areas or subcatchments it is useful to have two or more measurement locations. With a single measurement location, lumped modelling for different subcatchments could be inaccurate if applied without careful analysis of surface cover, slopes, flow paths and similar, i.e. if the catchment is "overlumped".

For extreme events even rough methods of measurement such as maximum level recording, are of great significance for urban creeks as well as for natural streams. 


\section{REFERENCES}

Despotović J. et al. (1998) Preliminary design project of stormwater and wastewater systems at the Kumodraz catchment, Technical Report 43295/98, Fac. Civ. Eng., Belgrade (In Serbian).

Despotović J., Petrović J., Zlatanović V., Jaćimović N., Đorđević S., Jovanović M., Đukić A., Babić B. and Prodanović D. (1999) Preliminary design for reconstruction of stormwater and wastewater system in developed urban area - A case study, Proc. 8th ICUSD, Sydney, pp. 721-729.

Đorđević S. (1999) BEMUS - BElgrade Model of Urban Sewer, Version 1.2, User Manual, Faculty of Civil Engineering, Belgrade.

Greenland Engineering Group (1997) Visual OTTHYMO 1.0, Concord, Ontario, Canada.

Petrović J. and Despotović J. (1998) Historical rainfall for urban storm drainage design. Wat. Sci. Tech., 37 (11), 105-111.

Vukmirović V. and Despotović, J. (1984) Statistical methods of storm analysis. Wat. Sci. Tech., 16 (8/9), 85-92. 